\title{
Reducing the embodied carbon of construction projects through a carbon emission encompassed tender
}

\author{
S. T. Ng \\ Department of Civil Engineering, The University of Hong Kong, \\ Hong Kong
}

\begin{abstract}
Fast speed construction development is a key contributor to excessive carbon emissions. Apart from the operational emissions of construction facilities, more and more clients and designers are concerned about the carbon emissions embodied in construction materials. Despite the significance of this, little research has been conducted to reduce the use of construction materials of high carbon intensity. To significantly reduce the carbon emissions due to the use of construction materials, a fundamental rethink of the tendering mechanism is needed. In this paper, a carbon emission encompassed tender is proposed. The fundamental basis of the envisaged carbon emission encompassed tender is a transparent and equitable framework to estimate the carbon footprint of products. With the release of the ISO14067, it is possible that the carbon footprint of construction materials can be systematically assessed at the product level. In this paper, the way in which the carbon footprint of construction materials is estimated is exemplified through a recently developed carbon labeling scheme. Then, the philosophy of the carbon emission encompassed tender is introduced. Finally, the challenges facing the implementation of the proposed carbon emission encompassed tender are highlighted. Through the carbon emission encompassed tender, contractors can get a reasonable reward to commensurate the carbon reduction attained through the use of low carbon construction materials.

Keywords: greenhouse gases, project carbon footprint, emission, reduction, emission-encompassed tender.
\end{abstract}




\section{Introduction}

Scientists generally accept that exacerbated greenhouse gas emissions are the root cause of climate change. To protect our future generations from climate change triggered catastrophes, it is imperative to keep the global temperature increase to less than $2^{\circ} \mathrm{C}$ by capping the atmospheric carbon dioxide $\left(\mathrm{CO}_{2}\right)$ concentrations to below 450 parts per million [1]. Achieving that requires that global emissions be cut down to between $60 \%$ and $75 \%$ of the 1990 levels by 2020 [2]. As a result, many countries have already introduced pragmatic measures to control carbon emissions.

Reducing the emissions of construction facilities is particularly vital to Hong Kong (HK) as $90 \%$ of end-use consumption of electricity is from the building sector [3]. In 2009, 37,694 million $\mathrm{kWh}$ of electricity were consumed due to building usage generating 24.5 million tons of $\mathrm{CO}_{2}$ equivalent $\left(\mathrm{tCO}_{2} \mathrm{e}\right)$ [4]. Harvey [5] argued that up to $80 \%$ of building energy can be minimized by bringing in best practices and novel design solutions to construction facilities. More attention should, therefore, be directed to the construction industry to help achieve the mission of carbon reduction.

Apart from addressing the problem from the upper stream of the construction supply chain through greater adoption of sustainable design concepts and energy efficient building services equipment, contractors may also contribute to carbon reduction as a sizeable volume of $\mathrm{CO}_{2}$ is originated from imported materials [6], material transportation [7] and site activity. Therefore, more stringent monitoring and control of $\mathrm{CO}_{2}$ emitted at the project level is indispensable [8].

Carbon offsetting has been promoted as a solution to reduce carbon emissions due to its economic and environmental efficiency [9]. In 2008, 4,213.5 million $\mathrm{tCO}_{2} \mathrm{e}$ of carbon costing more than US $\$ 120$ billion was transacted in the global market [10]. Nevertheless, the construction industry is fragmented and involves many stakeholders, and carbon trading may not be easy to implement at the project level. As "carbon has a similar priority as price" [11], clients should seriously consider how to phase in the carbon trading concept in their tendering systems.

Nowadays, more and more organizations realize their responsibility to the environment, and have introduced innovative sourcing process to lower the carbon footprint of their purchases [12]. According to Lee et al. [14], green purchasing should consider vendors' environmental performance along with other traditional factors such as time, costs, quality and flexibility. Construction clients should develop proactive and strategic carbon reduction approaches, which takes into account the entire construction process, to help improve contractors' environmental commitment.

In this paper, a carbon emission-encompassed tender (CEET) is proposed to incentivize contractors who can bring in novel ideas to cut down $\mathrm{CO}_{2}$ emissions of a construction project. The paper begins by exemplifying the concept behind CEET. A mechanism for measuring the carbon footprint of construction materials at the product level is then introduced. The paper is concluded by the 
challenges facing the construction industry for introducing the envisaged CEET concept.

\section{Model framework}

Notwithstanding the existence of mandatory systems like the clean development mechanism [14] and the off-the-counter trading in the voluntary markets, the amount of carbon emitted through the construction stage of a project may not justify the use of those mechanisms. Hence, there is a need to devise a practical system to encourage contractors contributing to carbon reduction. One way to achieve this is by awarding contracts to those who can come up with bright ideas to reduce $\mathrm{CO}_{2}$ emissions. Incorporating project carbon footprint as one of the determining factors in construction bid evaluation seems to be a feasible and logical step towards emission reduction [15].

Acknowledging the importance of maintaining fairness and transparency in bid evaluation, data pertinent to carbon emissions must be carefully solicited and analyzed. To improve consistency and reliability, the project carbon footprint should be systematically estimated according to an established framework which clearly sets out the major components of carbon emissions during the construction processes. The suggestion of IBM [16] in estimating the carbon footprint by considering the planning, sourcing, production and logistics along with the carbon footprint recording principles [17] may help formulate a framework for construction project carbon footprint accounting.

The project carbon footprint as estimated by bidders can then be compared with that of a "business-as-usual" design and construction scenario [9] to determine how much $\mathrm{CO}_{2}$ emissions can be saved by each contractor. A monetary value which is acceptable to the client can then be assigned to the carbon saving so that contractors' commitment to $\mathrm{CO}_{2}$ emission reduction can be considered along with their bid price [11]. The envisaged framework of CEET is shown Figure 1.

The notion of CEET is analogous to that of an alternative tender except that the carbon footprint of a project should first be determined by the client and/or design team based on the developed drawings and specifications. The project carbon footprint represents the emissions in a "business-as-usual" scenario, and this can be derived by making reference to the typical information as identified from the Inventory of Carbon and Energy database developed by the University of Bath and/or the Institution of Civil Engineers' CESMM4 Carbon \& Price Book [19]. The project carbon footprint should be disclosed to the tenderers at the tendering stage as it would serve as a baseline for subsequent comparison.

Should a tenderer be interested in submitting a low carbon proposal, the details of alternative construction materials and/or methods along with the magnitude of carbon reduction should be provided in CEET. Instead of using the norms as identified from established databases, the contractor should capture and rely on the actual carbon footprint of alternative construction materials and/or apply established methods to calculate the emission-conscious 
alternative(s). While the low carbon alternative(s) may involve extra costs, the tenderer should be allowed to reflect such costs and any possible cost savings in CEET.

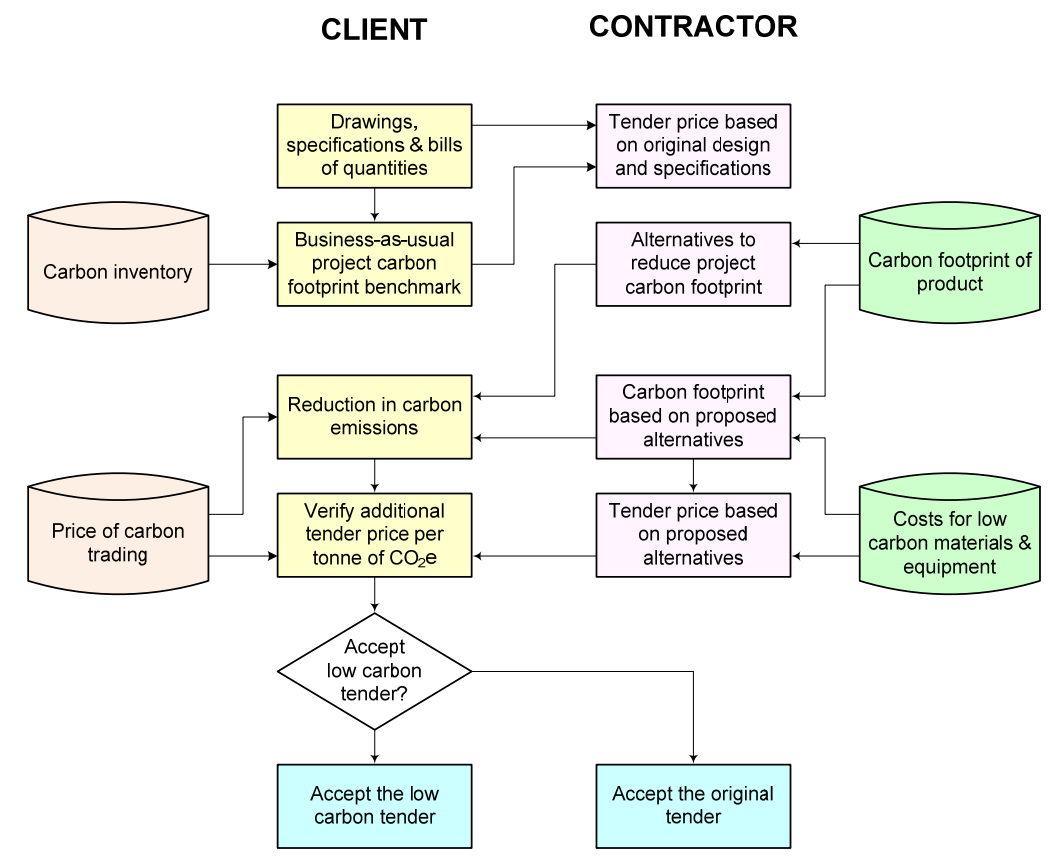

Figure 1: Conceptual framework of carbon emission-encompassed tender.

With the conforming tender and CEET, the client can make an informed decision to commensurate their carbon reduction goal and budgetary constrain. The comparison is not limited to determining how much additional cost is needed to achieve a specific amount of carbon reduction, but it would also facilitate the client to examine whether the low carbon initiative(s) being put forward by the tenderer is/are value for money or not by comparing that with the price of carbon in the market and the life cycle costs.

\section{Tracking and tracing project carbon footprint}

In recent years, many established standards are available to guide the measurement of $\mathrm{CO}_{2}$ emissions [19], and these include the European Union Emissions Trading Scheme [21], the European Union Renewable Energy Directive [22], the UK Standard Assessment Procedure for Energy Rating of Dwellings 2005 [23], etc.

Apart from that, various carbon footprint models or calculators, like the Carbon Footprint, Carbon Fund, Combat Climate Model, Grian, Resurgence, Safe Climate, etc., are available to calculate an individual's carbon footprint 
based on electricity, oil, gas or coal consumptions. Wiedmann and Minx [24] proposed calculating the carbon footprint methodologically based on a process analysis in the life cycle analysis (a bottom-up approach) or by means of an environmental input-output analysis using national or organizational financial statistics (a top-down approach).

Fieldson et al. [12] commented that these protocols tend to focus on organizational emissions and reporting. With the release of the Publicly Available Specification 2050 [25] and ISO/TS 14067:2013 Greenhouse Gases Carbon Footprint of Products - Requirements and Guidelines for Quantification and Communication [26], a robust and consistent approach for assessing the life cycle carbon emissions at the product level is now viable. From the perspective of both the client and contractor, an equitable mechanism to assess the carbon footprint of product is essential as this would allow an accurate calculation of $\mathrm{CO}_{2}$ reduction.

With the foresight of the Construction Industry Council in $\mathrm{HK}$, a carbon labeling scheme for the construction industry has recently been launched. The first phase of development covers six construction materials namely cement, reinforcing bar, structural steel, aluminum, tile, and external glass. The second phase of the development of the carbon labelling scheme is now underway, and carbon assessment frameworks for another ten construction materials namely concrete, precast concrete, aggregate, stainless steel, galvanized steel, cast iron, asphalt, brick and block, timber product, and gypsum board, are being developed.

The carbon footprint of a product is taken as the $\mathrm{CO}_{2}$ emitted during raw material extraction and the manufacturing process up to the point when the finished construction material is delivered to the border of Hong Kong. The assessment consists of direct emissions arising from raw material combustion, combustion of kiln fuels, and of non-kiln fuels. Any combustion of kiln fuels and those fuels used for drying and processing the raw materials should be taken into account. In addition, the combustion of non-kiln fuels which are not covered in the definition of kiln fuels, e.g. for quarrying or mining of raw materials, on-site transportation, room heating, etc. should also be accounted for. Apart from direct emissions, indirect $\mathrm{CO}_{2}$ emissions including external production of electricity consumed by the manufacturers, production of bought raw materials, third-party transportation, land use change and so on should also be reported.

The details of how to assess the carbon footprint of cement, reinforcing bar and structural steel are documented in the guidelines prepared by the Construction Industry Council. The carbon labeling scheme provides transparent and reliable product carbon footprint information to both the client and contractor for assessing any carbon reduction in CEET.

\section{Benchmarking and incentivizing regime}

Under the mandatory emissions reduction regime, projects would be awarded carbon emission reduction units if the carbon reduction is "additional to any that 
would occur in the absence of the project" [2]. Therefore, projects under the clean development mechanism must be compared with a baseline to quantify the carbon reduction. An emission-based additionality test is used to establish what would have happened without the clean development mechanism project [9].

Similarly, the voluntary market, such as the Chicago Climate Exchange, operates a cap-and-trade programmer, where their members are committed to annual carbon reductions as a percentage of their baseline. Reductions beyond the contracted level can be sold to the others [26]. Ruth et al. [15] argued that setting a benchmark at an aggregate production level does not allow emission reduction from a range of similar projects be accurately compared, and they have proposed a process-step benchmarking approach.

In the absence of an agreed benchmarking approach, it would be prudent to refer to the project carbon footprint when establishing the baseline. This should ensure projects of different types, scales, standards and complexity be compared on an equitable basis. The Hong Kong Housing Department has developed a Carbon and Energy Estimation (CEE) model to calculate the entire life cycle of public housing projects based on a 100-year building life. Using the CEE model, the carbon emissions pertinent to the material consumed, transportation of materials, energy consumed in communal areas, energy consumed by occupants, carbon removals, and disposal can be systematically analyzed at the project level. This should serve as a reliable and transparent basis for establishing the carbon footprint benchmark for a project.

In determining whether an emission-conscious alternative is worth pursuing or not, one should trade-off the carbon reduction against the cost, service and quality of the low carbon construction materials and methods being proposed. The client should leverage the reduction in project carbon footprint and any corresponding additional costs. In the voluntary market, the price for offsetting a ton of $\mathrm{CO}_{2}$ is governed by different offset service providers. As a result, the carbon offset prices may vary and could fluctuate with the market [27]. Clients should carefully verify the suitability of using those prices in the exchange market for incentivizing emission-conscious contractors. Another approach is to allow contractors to put the additional costs for using low carbon initiatives in their tender. With that, the market price of carbon can serve as a reference for comparing the CEET price put forward by the contractor.

\section{Challenges}

To unveil the challenges of implementing CEET in HK, semi-structured interviews were conducted with various stakeholders to capture their opinions. Of the 93 experts identified, 12 agreed to take part in the interview. The interviewees included those from the government, a developer, contractor, consultancy firm and non-government organization (NGO) (Table 1). 
Table 1: $\quad$ Interviewee profile.

\begin{tabular}{lll}
\hline Interviewee & Organization Type & Position \\
\hline A1 & Government Department & Senior Engineer \\
A2 & Government Department & Senior Engineer \\
A3 & Government Department & Senior Architect \\
A4 & Government Department & Senior Engineer \\
B1 & Developer & Assistant Technical Manager \\
B2 & Developer & Quantity Surveyor \\
C1 & Contractor & Project Environmental Engineer \\
C2 & Contractor & Project Engineer \\
C3 & Contractor & Senior Quantity Surveyor \\
C4 & Contractor & Senior Project Engineer \\
D1 & Consultant & Senior Engineer \\
E1 & Non-Government Organization & Corporate Member \\
\hline
\end{tabular}

\subsection{Obstacles}

\subsubsection{Lack of common goal}

While the idea of introducing CEET is to reduce the carbon footprint of construction projects, the interviewees from the government departments stressed that every stakeholder should align to this goal. Otherwise, CEET would become just another reward scheme with no significant impact to emission reduction at the construction stage. However, under the current cut-throat tendering mechanism, some contractors would strive to maximize their profit rather than investing energy in exploring low carbon alternatives.

\subsubsection{Additional costs}

According to the experts from the government, developer and NGO, CEET would inevitably lead to an increase in the capital cost of a construction project. The developers may not be willing to bear any excessive cost due to $\mathrm{CO}_{2}$ reduction. Some developers even suggested that the government should take a lead by introducing incentive schemes to motivate developers to cut down on the carbon emissions of their construction facilities. An increase in cost is one of the main reasons for clients to hold back as commented by some contractors interviewed.

\subsubsection{Immature technology}

Interviews from the government and NGO believed that only small numbers of contractors are capable of initiating new solutions to reduce the project carbon footprint. From the contractor's perspective, the knowhow of implementing the low carbon measures could be a major obstacle as their supervisory staff and workers would have to get themselves acquainted with the properties of low carbon materials and/or equipment. The limited choice of low carbon materials and/or equipment was also a concern of some contractors interviewed. The lack of knowledge could further increase their costs. 


\subsubsection{Project constraints}

The contractors were less optimistic on CEET as they are very much handicapped by the design and specifications developed by the client and design team. As a result, the low carbon alternatives which can be proposed by the contractors could be very limited. The contractors interviewed also pointed out that the project time, cost and quality are the most important aspects in a construction project and introducing any low carbon alternatives may jeopardize the project success. Unless the introduction of low carbon initiatives are equitably rewarded, there is not much incentive for them to take the risk.

\subsection{Key factors to success}

\subsubsection{Transparent system}

Despite the fact that the consultant interviewed believed that CEET can help consolidate the industry and improve contractors' confidence to develop low carbon construction technology, the government, developer, contractor and NGO emphasized the importance of developing a transparent system to measure carbon reduction and reward the contractor. According to the interviewees from the developer, sufficient resources should be directed to analysis whether time and quality will be affected by the low carbon alternatives. Constant reviews should be carried out to ensure the effectiveness of $\mathrm{CO}_{2}$ reduction as work progresses, as perceived by the interviewees from the government.

\subsubsection{Change in mindset}

From the contractors' perspective, a fundamental change in the mindset of the clients is needed so that the focus is no longer on minimizing the construction costs and time but on reducing the environmental impacts and carbon footprint of a construction facility. This is echoed by the developer and consultant interviewed which emphasized on the importance of a cultural change towards sustainable development. Achieving that necessitates close communications between the client, design team and contractor to establish which are the most feasible and effective low carbon alternatives through the construction stage, according to the contractor and NGO.

\subsubsection{Leadership}

With more and more companies realizing the importance of cooperate social responsibility and the adverse impact of carbon emissions, some contractors are willing to contribute to emission reduction on a voluntary basis. However, successful introduction of CEET would call for the leadership of the government and professional institutions, as opined by the government, developer, consultant and contractor interviewed. While developers are more skeptical on spending extra money in low carbon construction materials and/or equipment, the government should pilot CEET in some public works projects to explore the effectiveness of such scheme. 


\subsubsection{Education and training}

The government officials interviewed stressed the importance of education and training to equip construction stakeholders with the low carbon measures. They also believed that it is necessary to provide training to the clients and contractors to familiarize them with the CEET concept especially the way in which the project carbon footprint is calculated as this is still very new to many construction parties. This is echoed by the contractors interviewed as they considered it vital to understand the philosophy behind CEET so that they can submit low carbon tenders accurately.

\section{Conclusions}

In this paper, a CEET has been proposed to encourage contractors to identify innovative solutions to help reduce the carbon emission at project level. To ensure the contractor is equitably rewarded, it is necessary to identify the project carbon footprint based on a business as usual scenario. Based on that, a baseline can be established to benchmark against the carbon saving of the low carbon alternative. Acknowledging that any reduction in project carbon footprint may cost, the contractor is allowed to price the low carbon materials and/or equipment being proposed. The extra costs are compared with the price of carbon in the market to facilitate the client in making an informed decision.

One of the major challenges of CEET is how to systematically and accurately account for the carbon of low carbon construction materials. Thanks to the recently released ISO standard, the carbon footprint of a product can be calculated scientifically. More importantly, the Construction Industry Council in HK has just launched the carbon labeling scheme for construction materials. The scheme should provide a simple and reliable platform for clients and contractors to gauge the carbon emissions of construction materials at the product level. These should open up the opportunity for realizing CEET in the construction industry.

Despite that, there are a still a number of challenges ahead before CEET can be successfully introduced in practice. Examples of these include the inherent adversarial cultural of the construction industry and the lack of incentive for clients to move towards a low carbon construction philosophy. There is a need to change the current culture through the big support of the government and better training so that construction stakeholders would be aware of the benefits of low carbon construction not only to their own company through reduced life cycle costs but also to society by helping revert the impacts brought by climate change.

\section{Acknowledgements}

The author would like to thank the Construction Industry Council for funding this research study through the CIC's Research Funding Grants. The help of Miss Fanny P.Y. Chung is also gratefully acknowledged. 


\section{References}

[1] Baer, P. \& Mastrandrea, M., High Stakes: Designing Emissions Pathways to Reduce the Risk of Dangerous Climate Change, Institute for Public Policy Research, London, UK, 2006.

[2] UNFCCC, Analysis of Mitigation Potentials and Identification of Ranges of Emission Reduction Objectives of Annex I Parties - Draft Conclusion Proposed by the Chair, United Nations Framework Convention on Climate Change, Bonn, Germany, 2007.

[3] EPD, Guidelines to Account for and Report on Greenhouse Gas Emissions and Removals for Buildings (Commercial, Residential or Institutional Purposes) in Hong Kong, Environmental Protection Department and the Electrical and Mechanical Services Department, Government of Hong Kong Special Administrative Region, Hong Kong, 2011.

[4] EMSD, Hong Kong Energy End-use Data 2010, Electrical and Mechanical Services Department, Government of Hong Kong Special Administrative Region, Hong Kong, 2010.

[5] Harvey, L.D.D., A Handbook on Low-Energy Buildings and District Energy Systems: Fundamentals, Techniques, and Examples, James and James, London, 2006.

[6] DEFRA, Development of an Embedded Carbon Emissions Indicator, Department of Environment, Food and Rural Affairs, London, UK, 2008.

[7] Chan, K.W. \& Boehmer, K., Launching of ISO 14064 for greenhouse gas accounting and verification, ISO Management Systems, March-April, pp. 14-16, 2006.

[8] Smith, R.A., Kersey, J.R. \& Griffiths, P.J., The Construction Industry Mass Balance: Resource Use, Wasters and Emissions, Viridis and CIRIA, UK, 2003.

[9] Ecocycle Council, Important Environmental Aspects of the Building Sector, Ecocycle Council, Stockholm, Sweden (in Swedish), 2002.

[10] Kollmuss, A., Zink, H. \& Polycarp, C., Making Sense of the Voluntary Carbon Market: A Comparison of Carbon Offset Standards, Stockholm Environment Institute, WWF Germany, Germany, 2008.

[11] Hamilton, K., Sjardin, M., Shapiro, A. \& Marcello, T., Fortifying the Foundation: State of the Voluntary Carbon Market 2009, Ecosystem Marketplace and New Carbon Finance, Washington, DC, 2009.

[12] Fieldson, R., Rai, D. \& Sodagar, B., Towards a framework for early estimation of lifecycle carbon footprinting of buildings in the UK, Construction Information Quarterly, CIOB, 11(2), pp. 66-75, 2009.

[13] Gardiner, B., Briefing: delivering sustainable development through procurement, Proceedings of the Institution of Civil Engineers Engineering Sustainability, 160(ES3), pp. 113-114, 2007.

[14] Lee, A.H.I., Kang, H., Hsu, C. \& Hung, H., A green supplier selection model for high-tech industry, Expert Systems with Applications, 36(4), pp. 7917-7927, 2009. 
[15] Ruth, M., Worrell, E. \& Price, L. (2000) Evaluating Clean Development Mechanism Projects in the Cement Industry Using a Process-Step Benchmarking Approach, Ernest Orlando Lawrence Berkeley Laboratory, Berkeley, CA.

[16] HM Government, Securing the Future - Delivering UK Sustainable Development Strategy, HM Government, London, UK, 2005.

[17] IBM, Mastering Carbon Management - Balancing Trade-offs to Optimize Supply Chain Efficiency, IBM Corporation, New York, 2008.

[18] Chan, K.W. \& Boehmer, K., Launching of ISO 14064 for greenhouse gas accounting and verification, ISO Management Systems, March-April, pp. 14-16, 2006.

[19] ICE, CESMM4 - Civil Engineering Standard Method of Measurement, Institution of Civil Engineers, London, 2013.

[20] Johnson, E., Goodbye to carbon neutral: getting biomass footprints right, Environmental Impact Assessment Review, 29, pp. 165-168, 2009.

[21] European Commission, Commission Decision of 18 July 2997 Establishing Guidelines for the Monitoring and Reporting of Greenhouse Gas Emissions Pursuant to Directive 2003/87/EC of the European Parliament and of the Council, 2007/589/EC, European Commission, Brussels, Belgium, 2007.

[22] Renewable Energy Directive, Proposal for a Directive on the Promotion of the Use of Energy from Renewable Resources, European Commission, Brussels, Belgium, 2008.

[23] Standard Assessment Procedure, The Government's Standard Assessment Procedure for the Energy Rating of Dwellings, DEFRA, London, UK, 2008.

[24] Wiedmann, T. \& Minx, J., A Definition of Carbon Footprint, ISA-UK Research \& Consulting, Durham, UK, 2007.

[25] PAS, Publicly Available Specification 2050 - Specification for the Assessment of the Life Cycle Greenhouse Gas Emissions of Goods and Services, BSI British Standards, London, 2008.

[26] ISO, ISO/TS 14067:2013 Greenhouse Gases - Carbon Footprint of Products - Requirements and Guidelines for Quantification and Communication, International Organization for Standardization, Geneva, Switzerland, 2013.

[27] Ribón, L. \& Scott, H., Carbon Offset Providers in Australia 2007, Global Sustainability at RMIT University, Melbourne, Australia, 2007.

[28] David Suzuki Foundation, Purchasing Carbon Offsets: A Guide for Canadian Consumers, Businesses and Organizations, David Suzuki Foundation and Pembina Institute, Vancouver, BC, Canada, 2009. 